\title{
Microbial Profile Evaluation of Beef Steaks From Different Packaging and Retail Lighting Display Conditions
}

\author{
Keelyn E. Hanlon ${ }^{1}$, Joshua C. McCann ${ }^{2}$, Mark F. Miller ${ }^{1}$, Mindy M. Brashears ${ }^{1}$, Colton L. Smith ${ }^{1}$, \\ J. Chance Brooks ${ }^{1}$, and Jerrad F. Legako ${ }^{1 *}$ \\ ${ }^{1}$ Department of Animal and Food Sciences, Texas Tech University, Lubbock, TX 79409, USA \\ ${ }^{2}$ Department of Animal Sciences, University of Illinois, Urbana, IL 61801, USA \\ *Corresponding author. Email: jerrad.legako@ttu.edu (Jerrad F. Legako)
}

\begin{abstract}
To date, meat microbiology research has relied on culture-dependent methods. Amplicon sequencing technology provides a deeper look into the microbial community. This study set out to evaluate the bacterial community of fresh beef longissimus lumborum steaks exposed to retail packaging and display conditions. Four packaging treatments were assigned after fabrication $7 \mathrm{~d}$ postmortem: high-oxygen modified atmosphere packaging, overwrapped packages within a carbon monoxide tri-gas flushed motherbag, vacuum rollstock pouches, and traditional overwrap. After a 14-d dark storage, carbon monoxide motherbag overwrapped packages were removed from the motherbag, and packages were distributed to a retail lighting condition for $72 \mathrm{~h}$ of retail display: fluorescent, light emitting diode, or darkness. Aerobic plate count and psychrotrophic bacteria were enumerated, in addition to 16S ribosomal RNA sequencing of DNA for microbial profile investigation. Sampling occurred at fabrication ( $7 \mathrm{~d}$ ), end of dark storage ( $20 \mathrm{~d}$ ), and end of retail display (23 d). The V3-V4 regions of the $16 \mathrm{~S}$ bacterial ribosomal RNA gene were sequenced using the Illumina MiSeq platform (Illumina, San Diego, CA). Counts for aerobic plate count bacteria differed by packaging $(P=0.039)$ but not lighting $(P>0.05)$. Firmicutes and Proteobacteria were the dominate phyla identified but were not affected by packaging or lighting $(P>0.05)$. Traditional overwrapped packages displayed in darkness and fluorescence had a higher abundance of Carnobacterium compared with those displayed under light emitting diode $(P=0.05)$. Dark-stored samples had more Pseudomonas compared with fluorescent display, regardless of packaging type $(P=0.03)$. While packaging and lighting conditions had a minimal impact on the community composition, these data positively contribute to a baseline establishing bacterial community profiles of fresh beef steaks subjected to retail display. This foundation suggests that further work is needed to understand whether shifts are more likely to occur during extended shelf life or in other retail beef display conditions.
\end{abstract}

Key words: beef, 16S, microbiome, microflora, dark storage

Meat and Muscle Biology 5(1): 24, 1-9 (2021) doi:10.22175/mmb.11711

Submitted 25 November $2020 \quad$ Accepted 4 March 2021

\section{Introduction}

The study of microorganisms in fresh meat has predominantly focused on screening for pathogens or monitoring of prominent spoilage organisms to maintain shelf life. Although pathogens and prominent spoilage organisms are important, they do not make up the entirety of the fresh meat microbial community. While culture-based methods are standard in the meat industry, these methods overestimate bacterial species that are easily culturable and may miss the opportunity to represent those with no successful culturing methods (Dowd et al., 2008; Jarvis et al., 2018). These other members of the community have potential to influence behavior of the more prominent spoilage or pathogenic organisms. The use of DNA as a signature molecule for identifying community populations has significantly increased both the depth and scope of ability to understand microbial diversity in specific environments (Nocker et al., 2007). Using DNA extractions to amplify and study the 16s ribosomal RNA (rRNA) 
gene provides a better opportunity to understand the entire fresh meat microbial community and the relationship of these community members. This new approach has the potential to unlock significant novel understandings for the fresh meat industry.

Packaging type can alter shelf-life quality and performance. However, the effect of packaging type on microorganism species present has been determined using culture-based enumeration methods. Therefore, gaps exist in knowledge explaining how entire microbial populations are influenced by packaging type. Illuminated open refrigerated cases are most frequently used for display of fresh meat in retail markets. Lighting and fluctuating temperatures in these cases, however, challenge the shelf-life stability of fresh meat. Current culture-based methods are limited to specific target organisms or broadly enumerate overall bacterial growth. These limitations do not allow for broader understanding of bacterial makeup or community. A DNA-based approach to understand the bacterial community, however, does provide a useful mechanism to observe the broader bacterial composition. There is an industry need for research focused on understanding the entire fresh meat bacterial community. Providing a deeper understanding of the community could unlock better methods to mitigate spoilage organisms and manage product shelf life. This need includes work done to better understand the contribution of processing environments and retail display conditions, toward the final retail meat microbial profile. The objective of this study was to evaluate and define the microbial community composition of beef longissimus lumborum steaks subjected to case-ready packaging and retail display lighting conditions using DNA-based methods.

\section{Materials and Methods}

\section{Sample collection and display}

Beef striploins ( $n=8)$, USDA Choice (Institutional Meat Purchase Specifications \#180), were collected from a commercial federally inspected processor and transported to the Gordon W. Davis Meat Laboratory (Lubbock, TX). At $7 \mathrm{~d}$ postmortem, striploins were fabricated into seventeen 1.27 -cm-thick steaks. Care was taken to use separate clean trays, new gloves, and a sterile scalpel for opening of each striploin in order to reduce cross contamination between strips. One steak from each striploin —with order randomized—was sampled on fabrication day. Remaining steaks $(n=16)$ were assigned into one of 4 packaging treatments: highoxygen modified atmosphere packaging $\left(80 \% \mathrm{O}_{2}\right.$,
$20 \% \mathrm{CO}_{2}$ ), overwrapped packages consisting of steaks on polystyrene trays and wrapped with a polyvinyl chloride film (oxygen transmission rate $=8.6 \mathrm{~g}$ of $\mathrm{O}_{2} / \mathrm{m}^{2} /$ $24 \mathrm{~h}$ ) placed within a motherbag flushed with carbon monoxide-based tri-gas $\left(0.4 \% \mathrm{CO}, 30 \% \mathrm{CO}_{2}, 69.6 \%\right.$ $\mathrm{N}_{2}$ ), vacuum rollstock Multivac pouches, and traditional overwrap. The traditional overwrap product was held in vacuum packaging throughout storage, then placed onto polystyrene trays and wrapped with polyvinyl chloride film immediately before retail display. The carbon monoxide motherbag product was removed from the tri-gas flushed motherbag prior to retail display. Microbial sampling occurred for each treatment at $7 \mathrm{~d}$ (fabrication), $20 \mathrm{~d}$ (end of storage holding time and before retail display), and $23 \mathrm{~d}$ (post display) postmortem. For retail display, each package type was sorted into one of 3 lighting treatments: darkness (DARK) (put in a box and held in cold storage without exposure to light) or a refrigerated open multi-deck retail display case $\left(1.9^{\circ} \pm 2.5^{\circ} \mathrm{C}\right)$ with either light emitting diode (LED) or fluorescent (FL) continuous lighting for $72 \mathrm{~h}$ with a light intensity of 2,934.9 and 2,863.1 lux, respectively. All beef steaks were cold transported $\left(4^{\circ} \mathrm{C}\right)$ to the laboratory for immediate analysis.

\section{Enumeration}

Microbial enumeration was evaluated by aerobic plate counts (APC) and aerobic psychrotrophic plate counts (PPC). Each package was aseptically opened, and using a $50-\mathrm{cm}^{2}$ sterile template $(3 \mathrm{M}$ poultry template, USDA050; 3M, St. Paul, MN) each steak was sampled with a swab premoistened with $25 \mathrm{~mL}$ of sterile Buffered Peptone Water (BPW; Merck Millipore Sigma, Burlington, MA). After swabbing, the steak was immediately transferred into a sterile Whirl-Pak filter bag (Nasco, Fort Atkinson, WI) for the DNA extraction protocol. Swabs were stomached $2 \mathrm{~min}$ at $230 \mathrm{rpm}$ (Seward 400C; Metrohm USA Inc., Riverview, FL), before transferring $1 \mathrm{~mL}$ into $9 \mathrm{~mL}$ sterile BPW dilution blanks for 10-fold dilutions. Enumeration of APC bacteria was performed using APC Petrifilms (3M, St. Paul, MN), in duplicate, with incubation $48 \mathrm{~h}$ at $35^{\circ} \mathrm{C}$. For PPC enumerations, samples were spiral plated - in duplicate- to standard methods agar (Alpha Biosciences, Baltimore, MD), incubated $10 \mathrm{~d}$ at $4^{\circ} \mathrm{C}$. After incubation, APC Petrifilms were counted and read using the $3 \mathrm{M}$ Petrifilm Plate Reader (3M, St. Paul, MN). After incubation of PPC, plates were counted using the Spiral Biotech Q Count (version 2.0, Spiral Biotech, Norwood, MA). All raw count data for PPC and APC were recorded as colony forming unit (CFU) per $50 \mathrm{~cm}^{2}$. 


\section{Microbial profile}

On each sampling day, whole steaks were rinsed in filtered Whirl-Pak bags, using $90 \mathrm{~mL}$ of cold $\left(2^{\circ} \mathrm{C}-4^{\circ} \mathrm{C}\right)$ sterile BPW. Bags were gently hand massaged to encourage thorough mixing without warming the product or promoting fat smear. Enriched bags were placed at $2{ }^{\circ} \mathrm{C}$ in a pre-cooled programmable cold holding incubator (MIR-154-PE; PHCBI, Wood Dale, IL) for $1.5 \mathrm{~h}( \pm 0.5 \mathrm{~h})$ to harden lipid content. Following this rest period, the liquid portion was removed using a sterile serological pipette (VWR, Radnor, PA) and transferred to $50 \mathrm{~mL}$ RNase and DNase free sterile conical tubes (iTubes; Stellar Scientific, Baltimore, $\mathrm{MD})$. Conical tubes were centrifuged at $4,280 \times g$ for $20 \mathrm{~min}$ at $3^{\circ} \mathrm{C}$. Supernatant was removed, and pellet was resuspended in $2 \mathrm{~mL}$ cold $\left(4^{\circ} \mathrm{C}\right)$ sterile saline before transfer to a $2 \mathrm{~mL}$ DNase and RNase free microcentrifuge tube for the DNA extraction protocol following the DNeasy PowerFood Microbial kit (MO BIO Laboratories, Qiagen, Carlsbad, CA). All samples were eluted using $75 \mu \mathrm{L}$ elution buffer and immediately quantified using a NanoDrop spectrophotometer (Thermo Fisher Scientific, Waltham, MA). The extractions that were quantified as less than $30 \mathrm{ng} / \mu \mathrm{L}$ were excluded from sequencing. Extractions were stored frozen $\left(-20^{\circ} \mathrm{C}\right)$ for 2 mo prior to submission for sequencing.

\section{Sequencing}

From the available extractions, 123 samples were selected for 16S rRNA sequencing. A mock community was used as the positive control, and negative controls were incorporated into the run. The $341 \mathrm{~F}$ (5'-CCTACGGGNGGCWGCAG-3') and 805R (5'GACTACHVGGGTATCTAATCC- $3^{\prime}$ ) primers were used for amplification of the V3-V4 regions of the 16S bacterial rRNA gene (Integrated DNA Technologies, Coralville, IA). Purified amplicons were pooled and pair-end sequenced using the Illumina MiSeq platform according to recommended protocols (Illumina, San Diego, CA) by the Texas Tech University Center for Biotechnology and Genomics. Indexed libraries were prepared using the Nextera XT index kit, version 2, and sequenced using $2 \times 300 \mathrm{bp}$ reads.

\section{Enumeration data analysis}

For enumeration, bacterial counts were averaged between duplicate plates, transformed, and reported as $\log _{10} \mathrm{CFU} / 50 \mathrm{~cm}^{2}$. Enumeration data were analyzed using the analysis of variance PROC GLM function of SAS (version 9.4; SAS Institute, Inc., Cary, NC).
Within respective analysis considerations (APC or PPC), data were analyzed for a day effect (fabrication vs. storage vs. retail). At end of storage holding a packaging type effect was evaluated. At retail display end, results were evaluated for a lighting $\times$ packaging effect, followed by effects for lighting and packaging separately.

\section{$16 S$ data analysis}

Raw FASTQ files were de-multiplexed prior to trimming of adapters and primers. Quality filtering was performed with the $D A D A 2$ pipeline using the $\mathrm{R}$ statistical program (The R Foundation; Callahan et al., 2016). Forward and reverse reads were truncated to 280 and 230, respectively. Taxonomic assignments were made using the SILVA database (version 128; Quast et al., 2013; Callahan, 2017), through the genus level. Further processing and creation of total abundance output was done using the phyloseq $\mathrm{R}$ package, with rarefaction curves created using the vegan $\mathrm{R}$ package (McMurdie and Holmes, 2013; Oksanen et al., 2019). Graphics and data output figures were created using the ggplot2, Rbrewer, and dplyr R packages available. For alpha and beta diversity evaluation, samples were rarefied at 10,635 reads. Metrics used for alpha diversity included Chao1, Shannon, and observed operational taxonomic units (OTU) (Shannon and Weaver, 1949; Chao and Lee, 1992). For beta diversity, the weighted Unifrac metric was used (Lozupone and Knight, 2005).

Relative abundance output for bacteria present at $\geq 1 \%$ at the phylum or genus taxonomic level were analyzed using the PROC MIXED procedure of SAS. At storage end, data were analyzed with packaging type as a fixed effect and striploin as a covariant. Data from the end of retail display were analyzed for packaging, lighting, and packaging $\times$ lighting effects, with strip considered a covariate. In order to normalize the distribution of the residuals, relative abundance data were transformed using logit transformation $[\mathrm{z}=\log (p /(1-$ $p)$ )], with $p$ representing the relative abundance of each taxa, or using the boxcox transformation within SAS. Residuals were evaluated for normal distribution, using the Shapiro-Wilk test, and transformations employed accordingly. The LSMEANS values were back transformed (if necessary) using the formula $\left[p=10^{\mathrm{z}} /(1+\right.$ $\left.10^{z}\right)$ ] from logit transformed output for ease of interpretation. Alpha and beta diversity plots were generated with the phyloseq package using a $\log (\mathrm{x}+1)$ transformation. Differences in alpha diversity were determined using the PROC MIXED procedure in SAS. Using the 
vegan package in $\mathrm{R}$, ADONIS was run to generate PERMONOVA output for beta diversity interpretation with 9,999 permutations.

\section{Results and Discussion}

\section{Enumeration}

No lighting by packaging type interaction existed for APC or PPC $(P>0.05)$ at the end of retail display. Mean APC differed by sampling time, from $0.77 \mathrm{log}$ $\mathrm{CFU} / 50 \mathrm{~cm}^{2}$ on fabrication day to $3.79 \log \mathrm{CFU} / 50$ $\mathrm{cm}^{2}$ at the end of retail display $(P<0.0001)$ across all packaging types. Lighting did not impact APC or PPC at the end of display across any packaging type $(P>0.05)$. This enumeration was performed to parallel typical microbial enumeration methods in fresh meat shelf-life studies and validate that unusual patterns or spoilage did not occur. Considering 7-8 logs of aerobic bacteria as the threshold of spoilage, none of these samples during storage or retail display met or exceeded the end of microbial shelf life (Vieira et al., 2009). Psychrotrophic bacteria were higher than aerobic bacteria, but also did not exceed the spoilage limit. These enumeration data are consistent with results from similar studies of ground beef patties and beef tenderloin steaks exposed to retail display conditions (Brooks et al., 2008; Hoyle et al., 2009; Mansur et al., 2019).

\section{General sequencing results}

Of the 123 total samples sequenced, one was filtered out because of a small library size (231 reads). Of the 122 retained samples for downstream analysis, sequencing generated an average of 40,152 reads per sample (range 3,384 to 98,220). Taxa identification was $99.3 \%$ at the phylum level, $88.5 \%$ at the family level, and $74.4 \%$ at the genus level. From generation of a rarefaction curve, rarefaction was set at 10,635 in order to standardize library size for diversity metrics.

\section{Storage relative abundance}

At end of storage, 2,326 unique taxa were present in 28 samples. Four phyla were present across packaging types, with Firmicutes being most dominant (65.5\%), followed by Proteobacteria (34.3\%), and minimal representation by Actinobacteria and Cyanobacteria. Presence of Firmicutes $(P=0.34)$ and Proteobacteria $(P=0.32)$ did not differ by packaging type (Table 1$)$. Across all packaging types, at storage, 36 unique genera were identified. Genera that represented at least $1 \%$ of total reads across all samples are presented in Figure 1. Overall, the most commonly identified genera across packaging types included Carnobacterium, Pseudomonas, and Lactobacillus (Table 2). Other genera identified which made up at least $1 \%$ of total reads included Leuconostoc, Rahnella, HafniaObesumbacterium, and Lactococcus. At storage end, genera did not differ in abundance by packaging type $(P>0.05)$.

\section{Retail relative abundance}

At the end of retail display, 4,596 unique taxa were identified from 89 samples. Similar to the samples at the end of storage, Firmicutes and Proteobacteria were the dominating phyla detected (Table 3). Abundance of Firmicutes and Proteobacteria did not differ by lighting $(P=0.18$ and $P=0.19)$ or packaging $(P=0.80$ and $P=0.52)$. Relative abundance by genera at end of retail display can be seen in Table 4 . A packaging $\times$ light interaction occurred for abundance of Carnobacterium $(P=0.05)$. Within overwrap packages, LED lighting (25\%) inhibited relative abundance of Carnobacterium relative to FL and DARK ( $41 \%$ and $45 \%$ ) overwrapped packages. Abundance of Pseudomonas was greatest in samples stored in DARK (33\%) and lowest in samples from FL retail display $(17 \% ; P=0.03)$.

\section{Alpha diversity}

Alpha diversity at end of storage is shown in Figure 2. Alpha diversity describes the diversity within a single sample as a measure of richness and evenness.

Table 1. Effect of packaging type on phyla relative abundance least-squares means of steaks at the end of storage ${ }^{1}$

\begin{tabular}{lllll}
\hline \hline & & Packaging Type & & \\
\cline { 2 - 5 } Phylum & HIOX & CO & VAC & \\
\hline Firmicutes & 59.03 & 65.03 & 68.63 & 0.34 \\
Proteobacteria & 41.09 & 34.59 & 30.28 & 0.32 \\
\hline
\end{tabular}

${ }^{1} \mathrm{HIOX}=$ high-oxygen modified atmosphere packaging $\left(80 \% \mathrm{O}_{2}, 20 \% \mathrm{CO}_{2}\right) ; \mathrm{CO}=$ overwrapped packages placed within a motherbag flushed with carbon monoxide $\left(0.4 \% \mathrm{CO}, 30 \% \mathrm{CO}_{2}, 69.6 \% \mathrm{~N}_{2}\right)$; VAC = vacuum rollstock packaging; relative abundance = percentage of total bacteria sequences; phyla listed detected at greater than $1 \%$ relative abundance across all samples. 


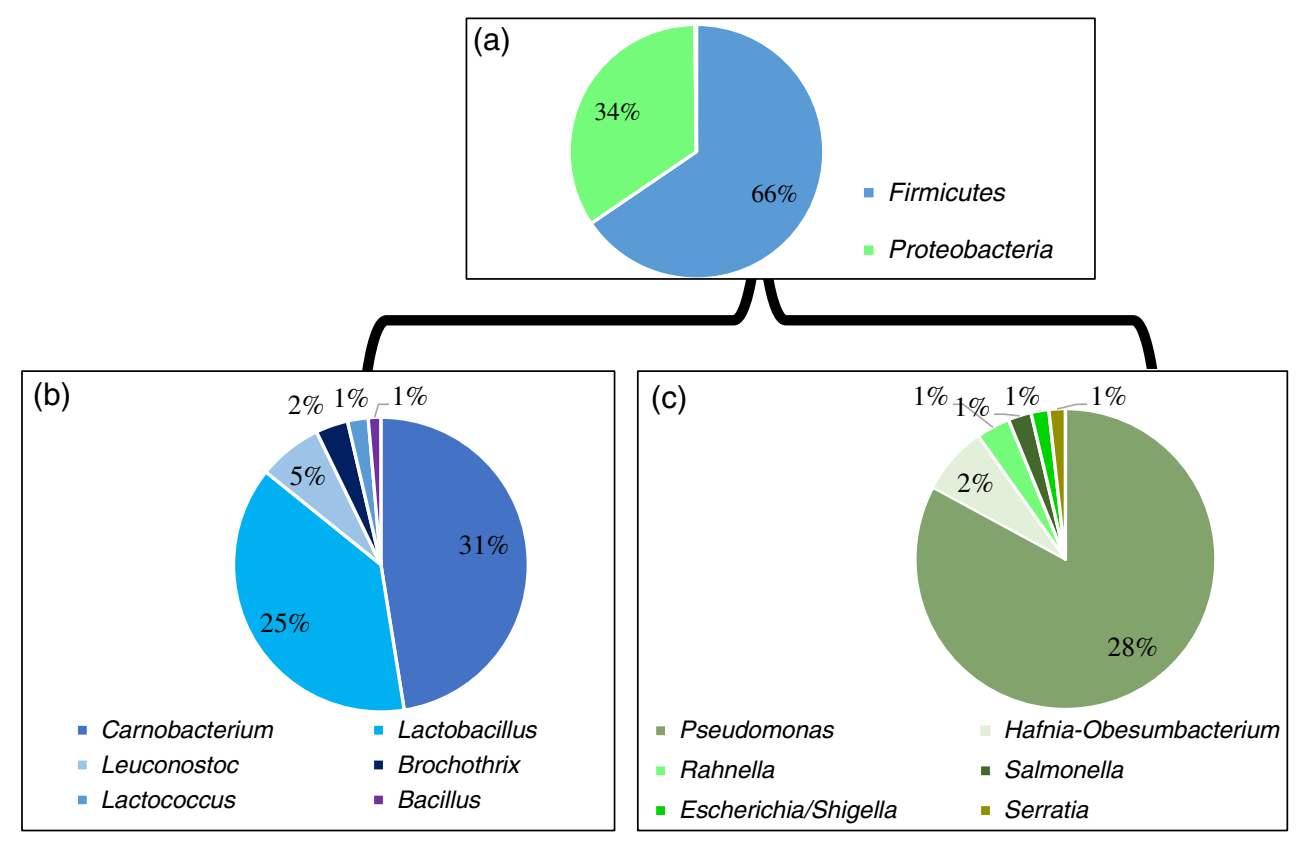

Figure 1. Taxonomic breakdown from storage samples, across packaging types (of bacteria representing $\geq 1 \%$ of total reads); (a) prevalence of phyla, relative to total abundance, in steaks at end of storage, across all packaging types, (b) community of genera belonging to Firmicutes phylum, (c) community of genera belonging to Proteobacteria.

Table 2. Effect of packaging type on genera relative abundance least-squares means of steaks at the end of storage ${ }^{1}$

\begin{tabular}{lcccc}
\hline & \multicolumn{2}{c}{ Packaging Type $^{1}$} & VAC & Palue \\
\cline { 2 - 5 } Genus & HIOX & CO & 51.65 & 0.79 \\
\hline Carnobacterium $^{2}$ & 54.24 & 49.07 & 22.88 & 0.31 \\
Pseudomonas $^{2}$ & 35.09 & 27.86 & 22.74 & 0.72 \\
Lactobacillus $^{2}$ & 16.92 & 20.71 & 2.29 & 0.20 \\
Leuconostoc $^{2}$ & 5.26 & 1.18 & 0.02 & 0.13 \\
Rahnella $^{2}$ & 0.80 & 0.00 & 0.12 & 0.79 \\
Hafnia-Obesumbacterium $_{\text {Lactococcus }^{2}}$ & 0.03 & 0.03 & 0.02 & 0.98 \\
\hline
\end{tabular}

${ }^{1} \mathrm{HIOX}=$ high-oxygen modified atmosphere packaging $\left(80 \% \mathrm{O}_{2}, 20 \% \mathrm{CO}_{2}\right) ; \mathrm{CO}=$ overwrapped packages placed within a motherbag flushed with carbon monoxide $\left(0.4 \% \mathrm{CO}, 30 \% \mathrm{CO}_{2}, 69.6 \% \mathrm{~N}_{2}\right)$; VAC = vacuum rollstock packaging; relative abundance = percentage of total bacteria sequences; genera listed detected at greater than $1 \%$ relative abundance across all samples.

${ }^{2}$ Logit transformation was used to normalize these genera, and least-squares means were back transformed for more clear interpretation.

Table 3. Relative abundance least-squares means of phyla at the end of retail display across packaging types ${ }^{1}$ and light ${ }^{2}$ display conditions

\begin{tabular}{|c|c|c|c|c|c|c|c|c|c|c|c|c|c|c|c|}
\hline \multirow[b]{2}{*}{ Phylum } & \multicolumn{3}{|c|}{ HIOX } & \multicolumn{3}{|c|}{ OW } & \multicolumn{3}{|c|}{$\mathrm{CO}$} & \multicolumn{3}{|c|}{ VAC } & \multicolumn{3}{|c|}{$P$ Value } \\
\hline & FL & LED & Dark & FL & LED & Dark & FL & LED & Dark & FL & LED & Dark & Pack & Light & Pack x light \\
\hline Firmicutes & 70.6 & 77.2 & 54.9 & 77.0 & 60.4 & 67.5 & 70.1 & 75.5 & 55.1 & 66.4 & 56.1 & 62.4 & 0.80 & 0.18 & 0.46 \\
\hline Proteobacteria & 26.7 & 21.4 & 41.3 & 22.7 & 38.4 & 31.5 & 29.2 & 23.8 & 43.8 & 31.2 & 51.8 & 36.5 & 0.52 & 0.19 & 0.33 \\
\hline
\end{tabular}

${ }^{1} \mathrm{HIOX}=$ high-oxygen modified atmosphere packaging $\left(80 \% \mathrm{O}_{2}, 20 \% \mathrm{CO}_{2}\right) ; \mathrm{CO}=$ overwrapped packages placed within a motherbag flushed with carbon monoxide $\left(0.4 \% \mathrm{CO}, 30 \% \mathrm{CO}_{2}, 69.6 \% \mathrm{~N}_{2}\right) ; \mathrm{VAC}=$ vacuum rollstock packaging; $\mathrm{OW}=$ traditional overwrap package; relative abundance = percentage of total bacteria sequences; genera listed detected at greater than $1 \%$ relative abundance across all samples.

${ }^{2} \mathrm{DARK}=$ samples not exposed to any lighting for 72 -h period; $\mathrm{FL}=$ samples exposed to fluorescent lighting for 72 -h display period; $\mathrm{LED}=$ samples exposed to light emitting diode display lighting for 72-h display period. 
Table 4. Relative abundance least-squares means of genera at end of retail display across packaging types ${ }^{1}$ and light $^{2}$ display

\begin{tabular}{|c|c|c|c|c|c|c|c|c|c|c|c|c|c|c|c|}
\hline \multirow[b]{2}{*}{ Genus } & \multicolumn{3}{|c|}{ HIOX } & \multicolumn{3}{|c|}{ OW } & \multicolumn{3}{|c|}{$\mathrm{CO}$} & \multicolumn{3}{|c|}{ VAC } & \multicolumn{3}{|c|}{$P$ Value } \\
\hline & FL & LED & Dark & FL & LED & Dark & FL & LED & Dark & FL & LED & Dark & Pack & Light & Pack x light \\
\hline Carnobacterium & $34.6^{\mathrm{abcd}}$ & $46.1^{\mathrm{a}}$ & $31.7^{\mathrm{abcd}}$ & $40.7^{\mathrm{abcd}}$ & $25.2^{\mathrm{d}}$ & $44.6^{\mathrm{abc}}$ & $45.8^{\mathrm{a}}$ & $45.0^{\mathrm{ab}}$ & $32.2^{\mathrm{abcd}}$ & $41.4^{\mathrm{abcd}}$ & $27.9^{\mathrm{bcd}}$ & $27.7^{\mathrm{cd}}$ & 0.39 & 0.28 & 0.05 \\
\hline Pseudomonas & 12.1 & 20.7 & 36.8 & 17.4 & 34.9 & 27.1 & 24.3 & 23.0 & 37.9 & 15.8 & 36.0 & 30.3 & 0.87 & 0.03 & 0.62 \\
\hline Lactobacillus & 22.8 & 13.4 & 13.6 & 21.5 & 28.7 & 13.9 & 14.6 & 22.8 & 09.7 & 12.1 & 12.7 & 26.5 & 0.73 & 0.73 & 0.25 \\
\hline Leuconostoc & 01.6 & 02.7 & 03.1 & 01.3 & 01.1 & 03.2 & 02.4 & 01.7 & 02.3 & 01.5 & 03.5 & 02.4 & 0.71 & 0.24 & 0.62 \\
\hline $\begin{array}{l}\text { Hafnia- } \\
\text { Obesumbacterium }\end{array}$ & 01.4 & 00.7 & 00.1 & 00.7 & 00.2 & 00.2 & 00.3 & 00.5 & 00.8 & 00.2 & 00.4 & 01.2 & 0.96 & 0.97 & 0.50 \\
\hline Lactococcus & 00.4 & 00.4 & 00.7 & 00.2 & 00.6 & 02.2 & 02.2 & 01.3 & 00.6 & 00.5 & 00.2 & 03.9 & 0.61 & 0.24 & 0.31 \\
\hline Rahnella & 00.9 & 00.3 & 00.4 & 00.7 & 01.0 & 01.0 & 00.4 & 00.2 & 00.5 & 00.2 & 01.4 & 00.7 & 0.37 & 0.41 & 0.32 \\
\hline Serratia & 00.4 & 00.3 & 00.3 & 00.1 & 00.3 & 00.3 & 00.3 & 00.1 & 00.7 & 00.3 & 01.2 & 00.3 & 0.63 & 0.72 & 0.37 \\
\hline
\end{tabular}

${ }^{1} \mathrm{HIOX}=$ high-oxygen modified atmosphere packaging $\left(80 \% \mathrm{O}_{2}, 20 \% \mathrm{CO}_{2}\right) ; \mathrm{CO}=$ overwrapped packages placed within a motherbag flushed with carbon monoxide $\left(0.4 \% \mathrm{CO}, 30 \% \mathrm{CO}_{2}, 69.6 \% \mathrm{~N}_{2}\right)$; VAC = vacuum rollstock packaging; $\mathrm{OW}=$ traditional overwrap package; relative abundance = percentage of total bacteria sequences; genera listed detected at greater than $1 \%$ relative abundance across all samples.

${ }^{\mathrm{a}-\mathrm{d} D i f f e r e n t}$ letters within a row indicate significant differences due to pack $x$ light effect $(P=0.05)$.

${ }^{2} \mathrm{DARK}=$ samples not exposed to any lighting for 72 -h period; $\mathrm{FL}=$ samples exposed to fluorescent lighting for 72 -h display period; LED $=$ samples exposed to light emitting diode display lighting for 72-h display period.

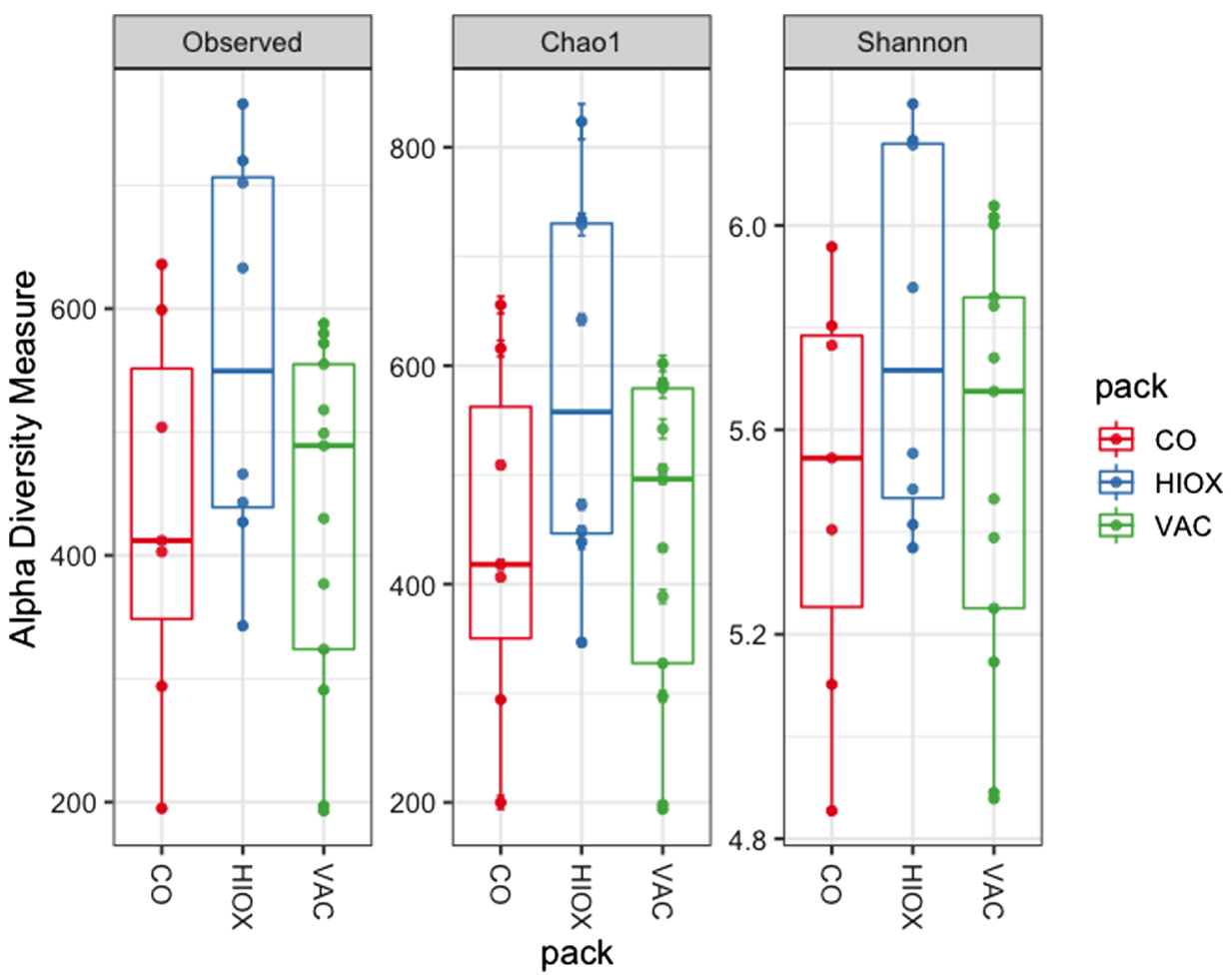

Figure 2 Alpha diversity by packaging type after storage. Alpha diversity did not differ by packaging type $(P>0.05)$. CO = traditional overwrapped packages placed within a motherbag flushed with carbon monoxide $\left(0.4 \% \mathrm{CO}, 30 \% \mathrm{CO}_{2}, 69.6 \% \mathrm{~N}_{2}\right)$; $\mathrm{HIOX}=$ high-oxygen modified atmosphere packaging $\left(80 \% \mathrm{O}_{2}, 20 \% \mathrm{CO}_{2}\right) ; \mathrm{VAC}=$ vacuum rollstock packaging.

Packing type at end of storage did not affect $(P>0.05)$ any measure of alpha diversity evaluated, observed OTU, Chao1, and Shannon index. At end of retail, DARK samples had greater Shannon diversity values than LED displayed samples (5.7 and 5.4, respectively;
$P=0.03)$. No differences occurred with observed OTU or Chao1 metrics $(P>0.05)$. These data indicate that LED lighting has a selective effect on the overall diversity of the community compared with DARK samples. 


\section{Beta diversity}

The weighted Unifrac was used to determine beta diversity at end of storage, prior to retail display. This metric considers the diversity between samples while considering phylogenetic relationships and differences in relative abundance. Packaging type did not influence beta diversity at end of storage $(P>0.05)$. Individual striploin origin, however, did have an impact on beta diversity as seen in Figure $3(P=0.003)$. Thus, the initial microbial community on each striploin has a greater impact on the community diversity at end of storage than packaging type. Retail beta diversity was determined using the unweighted Unifrac values. Beta diversity was not significantly influenced by packaging type or lighting $(P>0.05)$. Striploin did not have a significant impact on beta diversity as seen in storage end samples $(P>0.05)$. This indicates that after the pressures of additional aging time and retail display conditions, beef steaks did not have notable differences in community diversity, regardless of striploin animal origin.

\section{Discussion of microbial profile results}

The predominate phyla found in this study, at both storage and retail end, were Firmicutes and Proteobacteria. While presently there are no studies investigating the predominant phyla of whole beef steaks in

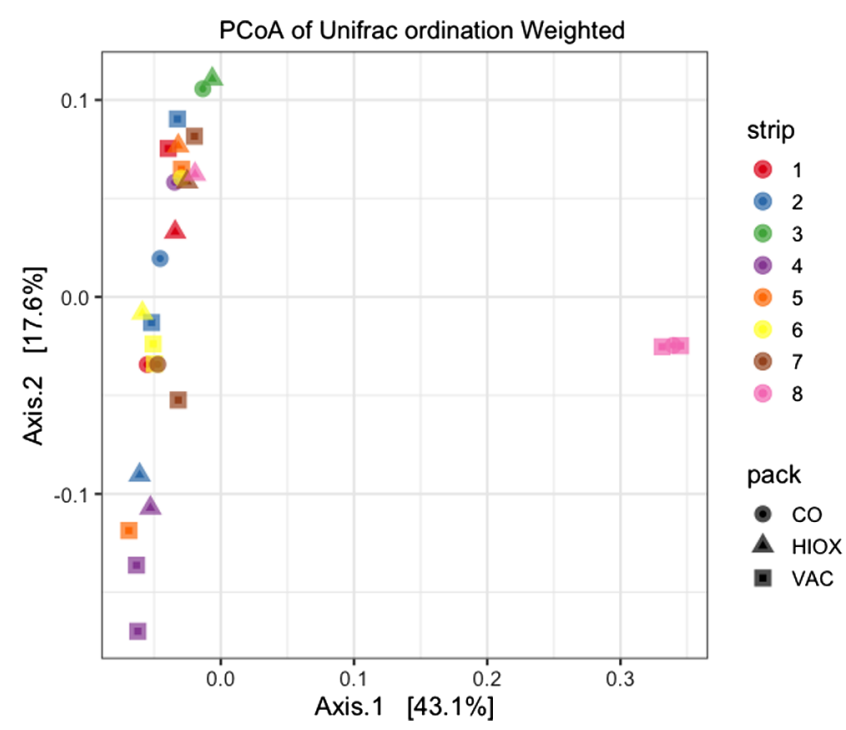

Figure 3 Beta diversity as expressed by weighted Unifrac PCoA plot at end of storage by packaging type and striploin origin. Beta diversity did not differ by packaging type $(P>0.05)$; however, beta diversity did differ by striploin origin $(P=0.003)$. $\mathrm{CO}=$ traditional overwrapped packages placed within a motherbag flushed with carbon monoxide $\left(0.4 \% \mathrm{CO}, 30 \% \mathrm{CO}_{2}\right.$, $\left.69.6 \% \mathrm{~N}_{2}\right)$; HIOX = high-oxygen modified atmosphere packaging $(80 \%$ $\left.\mathrm{O}_{2}, 20 \% \mathrm{CO}_{2}\right)$; VAC $=$ vacuum rollstock packaging. the U.S., other work investigating the microbiome of fresh ground beef has also established these 2 phyla as dominant (Vikram et al., 2018; Weinroth et al., 2019). However, Weinroth et al. (2019) found that Proteobacteria made up a much smaller component of the microbial community in ground beef than was found in this study of beef steaks. In Europe, meat products are more commonly dominated by Firmicutes and Actinobacteria, whereas Proteobacteria and Bacteroidetes are more present in fresh seafood (Chaillou et al., 2015). With limited research in this area, it should be noted that differences in interventions, sample processing, and extraction procedures would have a major effect on the observed phyla proportions.

Following a system outlined by Hwang et al. (2020), the most abundant genera found in the present study would all be classified as potential spoilage organisms, except Rahnella, which is classified as a common bacterium to the fresh meat microbiome. The microbiome of beef tenderloin has been shown to be made up of Leuconostocaceae (51\%), Lactobacillaceae (23\%), and Pseudomonadaceae (18\%), with the percentage of Pseudomonadaceae increasing to dominate over $74 \%$ of the total population at end of shelf life (Mansur et al., 2019). While Leuconostocaceae, Lactobacillaceae, and Pseudomonadaceae were all identified on these beef steaks, Carnobacterium was the predominant genus and was present in both storage end and retail end samples, regardless of treatment. Carnobacterium, Lactobacillus, Leuconostoc, and Lactococcus are all lactic acid bacteria (LAB), and LAB are commonly associated with negative spoilage behavior of fresh meat (James and James, 2000; Remenant et al., 2015). Pseudomonas, when present in high enough concentrations to cause spoilage, is known for producing slime, sulfides, esters, and amines (Lambert et al., 1991).

With bacterial enumeration, it is well established that concentrations of bacteria present on the product increase with time, especially at retail display temperatures (Brooks et al., 2008; Hoyle et al., 2009; Mansur et al., 2019). With this in mind, product packaging is selected to maximize color stability and product shelf life while controlling microbial growth. Vacuum packaging typically creates an environment that is more favorable for $\mathrm{LAB}$ and selective against the success of Pseudomonas spp. (Lavieri and Williams, 2014). However, this selection was not observed in the current study as abundance of Pseudomonas did not differ by packaging type. This contradiction highlights the further need to understand the microbial community as a whole through fresh meat shelf life beyond what is 
understood based on culture-based methods. This result could suggest that vacuum packaging is not simply suppressing viability but instead reducing the metabolic activity of Pseudomonas spp. While the expected bacterial response during meat retail display is based on research done using culture-based methods, 16S rRNA sequencing alone does not describe metabolic activity of detected organisms. Future work may need to employ RNA-based methods such as metatranscriptome sequencing to capture relevant differences that may also contribute to spoilage prevention (Kovac et al., 2017).

Although the results from this study did not identify a particular packaging type or lighting condition to exert distinctive selection pressure, some important differences were identified. In the present study, LED lighting appeared to inhibit Carnobacterium found in overwrap packages when compared with DARK and FL samples. This is in disagreement with results found by Steele et al. (2016) in which neither LED nor FL lighting inhibited aerobic bacteria on pork loin chops. In this study of beef steaks, Pseudomonas was found to more abundant in DARK samples compared with FL retail displayed samples. DARK retail samples also had higher Shannon diversity than LED displayed samples. While lighting is less widely studied than packaging conditions of retail meat, lighting appeared to have a greater influence on the meat microbial community than packaging. One study found cultured Enterobacteriaceae populations to decrease on beef longissimus lumborum steaks displayed under FL lighting, with increased growth on steaks under LED lighting (Steele et al., 2016).

To date, published research to establish the core microbiome of fresh beef during ordinary retail processing and display conditions is limited. It is notable that methods employed in this study were successful in generating high-quality sequencing reads from DNA extractions, ultimately leading to less filtering of samples than some of the previous work done to date. This suggests that the methods used in this study enabled full representation of the study scope the authors set out to evaluate.

\section{Conclusions}

From this study, the predominant phyla identified on beef longissimus lumborum steaks were Proteobacteria and Firmicutes. Two genera, Pseudomonas and Carnobacterium, were influenced by retail lighting. Pseudomonas was more abundant in dark retail samples than LED packages, regardless of packaging type. Conversely, Carnobacterium in traditional overwrap samples were inhibited in LED lighting when compared with DARK and FL. These results suggest that light exposure of retail packages may have an impact on abundance of some genera found on fresh beef steaks. The information produced from this study is valuable to understand the microbial community composition of fresh beef steaks, through commonly used industry packaging and lighting display conditions.

Although more work has been done looking at the microbiome of ground beef, gaps remain in the published research to date applying this technology to subprimals and retail whole-muscle beef cuts. To our knowledge, this is the first study evaluating the bacterial profile of fresh steaks, with treatments of packaging and retail lighting conditions. Future work in this area will contribute to further understanding about whether packaging type and retail display conditions influence the microbial profile of fresh beef steaks, especially through more extended aging conditions.

\section{Acknowledgments}

This project was funded in part by the Beef Checkoff.

\section{Literature Cited}

Brooks, J. C., M. Alvarado, T. P. Stephens, J. D. Kellermeier, A. W. Tittor, M. F. Miller, and M. M. Brashears. 2008. Spoilage and safety characteristics of ground beef packaged in traditional and modified atmosphere packages. J. Food Protect. 71:93301. https://doi.org/10.4315/0362-028x-71.2.293.

Callahan, B. J. 2017. Silva taxonomic training data formatted for DADA2 (Silva version 128) [Data set]. Zenodo. https://doi. org/10.5281/zenodo.801831. (Accessed 20 April 2019).

Callahan, B. J., K. Sankaran, J. A. Fukuyama, P. J. McMurdie, and S. P. Holmes. 2016. Bioconductor workflow for microbiome data analysis: From raw reads to community analysis [version 2; peer review: 3 approved]. F1000Research. 5:1492. https:// doi.org/10.12688/f1000research.8986.2.

Chaillou, S., A. Chaulot-Talmon, H. Caekebeke, M. Cardinal, S. Christieans, C. Denis, M. H. Desmonts, X. Dousset, C. Feurer, E. Hamon, J. J. Joffraud, S. La Carbona, F. Leroi, S. Leroy, S. Lorre, S. Macé, M. F. Pilet, H. Prévost, M. Rivollier, D. Roux, R. Talon, M. Zagorec, M. C. Champomier-Vergès. 2015. Origin and ecological selection of core and food-specific bacterial communities associated with meat and seafood spoilage. ISME J. 9:1105-1118. https://doi.org/10.1038/ismej.2014.202.

Chao, A., and S. M. Lee. 1992. Estimating the number of classes via sample coverage. J. Am. Stat. Assoc. 87:210-217. https://doi. org/10.2307/2290471.

Dowd, S. E., T. R. Callaway, R. D. Wolcott, Y. Sun, T. McKeehan, R. G. Hagevoort, and T. S. Edrington. 2008. Evaluation of the 
bacterial diversity in the feces of cattle using 16S rDNA bacterial tag-encoded FLX amplicon pyrosequencing (bTEFAP). BMC Microbiol. 8:125. https://doi.org/10.1186/1471-2180$8-125$.

Hoyle, A. R., J. C. Brooks, L. D. Thompson, W. Palmore, T. P. Stephens, and M. M. Brashears. 2009. Spoilage and safety characteristics of ground beef treated with lactic acid bacteria. J. Food Protect. 72:2278-2283. https://doi.org/10.4315/ 0362-028x-72.11.2278.

Hwang, B. K., H. Choi, S. H. Choi, and B. S. Kim. 2020. Analysis of microbiota structure and potential functions influencing spoilage of fresh beef meat. Front. Microbiol. https://doi. org/10.3389/fmicb.2020.01657.

James, S. J., and C. James. 2000. Refrigerated meat quality: Microbiology of refrigerated food. In: Meat refrigeration. CRC Press LLC, Boca Raton, FL. pp. 3-11.

Jarvis, K. G., N. Daquigan, R. J. White, P. M. Morin, L. M. Howard, J. E. Manetas, A. Ottesen, P. Ramachandran, and C. J. Grim. 2018. Microbiomes associated with foods from plant and animal sources. Front. Microbiol. https://doi.org/ 10.3389/fmicb.2018.02540.

Kovac, J., H. den Bakker, L. M. Carrol, and M. Wiedmann. 2017. Precision food safety: A systems approach to food safety facilitated by genomics tools. TRAC-Trend. Anal. Chem. 96:52-61. https://doi.org/10.1016/j.trac.2017.06.001.

Lambert, A. D., J. P. Smith, and K. L. Dodds. 1991. Shelf life extension and microbiological safety of fresh meat-A review. Food Microbiol. 8:267-297. https://doi.org/10.1016/ S0740-0020(05)80002-4.

Lavieri, N., and S. K. Williams. 2014. Effects of packaging systems and fat concentrations on microbiology, sensory and physical properties of ground beef stored at $4 \pm 1^{\circ} \mathrm{C}$ for 25 days. Meat Sci. 97:534-541. https://doi.org/10.1016/j.meatsci. 2014.02.014.

Lozupone, C., and R. Knight. 2005. UniFrac: A New Phylogenetic Method for Comparing Microbial Communities. Appl. Environ. Microb. 71:8228-8235. https://doi.org/10.1128/ AEM.71.12.8228-8235.2005.

Mansur, A. R., E. J. Song, Y. S. Cho, Y. D. Nam, Y. S. Choi, D. O. Kim, D. H. Seo, and T. G. Nam. 2019. Comparative evaluation of spoilage-related bacterial diversity and metabolite profiles in chilled beef stored under air and vacuum packaging. Food Microbiol. 77:166-172. https://doi.org/10.1016/j. fm.2018.09.006.

McMurdie, P. J., and S. Holmes. 2013. phyloseq: An R package for reproducible interactive analysis and graphics of microbiome census data. PLoS One. 8:e61217. https://doi.org/10.1371/ journal.pone.0061217.

Nocker, A., M. Burr, and A. K. Camper. 2007. Genotypic microbial community profiling: A critical technical review. Microb. Ecol. 54:276-289. https://doi.org/10.1007/s00248-006-9199-5.

Oksanen, J., F. G. Blanchet, M. Friendly, R. Kindt, P. Legendre, D. McGlinn, P. R. Minchin, R. B. O’Hara, G. L. Simpson, P. Solymos, M. H. H. Stevens, E. Szoecs, and H. Wagner. 2019. vegan: Community Ecology Package. R package version 2.5-6. https://CRAN.R-project.org/package=vegan. (Accessed 30 August 2019).

Quast, C., E. Pruesse, P. Yilmaz, J. Gerken, T. Schweer, P. Yarza, J. Peplies, and F. O. Glöckner. 2013. The SILVA ribosomal RNA gene database project: Improved data processing and web-based tools. Nucleic Acids Res. 41:D590-D596. https://doi.org/10.1093/nar/gks1219.

Remenant, B., E. Jaffres, X. Dousset, M. F. Pilet, and M. Zagorec. 2015. Bacterial spoilers of food: Behavior, fitness and functional properties. Food Microbiol. 45:45-53. https://doi.org/ 10.1016/j.fm.2014.03.009.

Shannon, C. E., and W. Weaver. 1949. The mathematical theory of communication. Urbana, IL: The University of Illinois Press. p. 1-117.

Steele, K. S., M. J. Weber, E. A. E. Boyle, M. C. Hunt, A. S. Lobaton-Sulabo, C. Cundith, Y. H. Hiebert, K. A. Abrolat, J. M. Attey, S. D. Clark, D. E. Johnson, and T. L. Roenbaugh, 2016. Shelf life of fresh meat products under LED or fluorescent lighting, Meat Sci. 117:75-84. https:// doi.org/10.1016/j.meatsci.2016.02.032.

Vieira, C., M. T. Diaz, B. Martinez, and M. D. Garcia-Cachan. 2009. Effect of frozen storage conditions (temperature and length of storage) on microbiological and sensory quality of rustic crossbred beef at different states of ageing. Meat Sci. 83:398-404. https://doi.org/10.1016/j.meatsci.2009. 06.013 .

Vikram, A., E. Miller, T. M. Arthur, J. M. Bosilevac, T. L. Wheeler, and J. W. Schmidt. 2018. Similar levels of antimicrobial resistance in U.S. food service ground beef products with and without a "raised without antibiotics" claim. J. Food Protect. 81:2007-2018. https://doi.org/10.4315/0362-028X. JFP-18-299.

Weinroth, M. D., B. C. Britton, K. R. McCullough, J. N. Martin, I. Geornaras, R. Knight, K. E Belk, and J. L. Metcalf. 2019. Ground beef microbiome changes with antimicrobial decontamination interventions and product storage. PLoS One. 14: e0217947. https://doi.org/10.1371/journal.prone.0217947. 